\title{
OURICURI
}

\section{FLORAÇÃO E BIOLOGIA FLORAL DO MAXIXEIRO}

\author{
Thiago Francisco de Souza CARNEIRO NETO ${ }^{1}$; Gleydson Brenno dos Santos SILVA ${ }^{1}$; Sebastião \\ Venancio de ALMEIDA NETO2; Rayla Mirele Passos RODRIGUES ${ }^{3}$; Moisés de Souza FEITOSA ${ }^{3}$; \\ Poliana Martins DUARTE*; Natália Campos da SILVA ${ }^{5}$; Kátia Maria Medeiros de SIQUEIRA ${ }^{6}$ \\ 'Bolsistas de Iniciação Científica FAPESB, Graduando em Engenharia Agronômica, Departamento de \\ Tecnologia e Ciências Sociais, Campus III, Universidade do Estado da Bahia, e-mail: \\ thiagofs_10@hotmail.com \\ 2 Bolsista de Iniciação Científica CNPq, Graduando em Engenharia Agronômica, Departamento de \\ Tecnologia e Ciências Sociais, Campus III, Universidade do Estado da Bahia. \\ ${ }^{3}$ Graduandos em Engenharia Agronômica, Departamento de Tecnologia e Ciências Sociais, Campus III, \\ Universidade do Estado da Bahia. \\ ${ }^{4}$ Mestranda em Fitotecnia, Departamento de Agronomia, Universidade Federal do Ceará. \\ ${ }^{5}$ Mestranda em Agronomia (Horticultura Irrigada), Universidade do Estado da Bahia. \\ 6Professora Titular do Departamento de Tecnologia e Ciências Sociais, Campus III, Universidade do Estado \\ da Bahia. \\ http://doi.org/10.29327/ouricuri.v8.i1.a6
}

\begin{abstract}
Resumo: A produção do maxixeiro é quase que exclusivamente de forma subespontânea resultando em baixo rendimento e qualidade de frutos. Estudos evidenciam que a produção de maxixe depende da polinização cruzada realizada principalmente por abelhas que realizam este processo ao visitar as flores. Pouco se conhece sobre a biologia floral do maxixeiro. Desta forma, o objetivo desse trabalho foi registrar o período de floração, a relação sexual entre os tipos florais e aspectos da biologia floral como a viabilidade e germinação polínica, receptividade do estigma, volume de néctar e a quantidade de grãos de pólen por antera. O experimento foi conduzido em área experimental no Departamento de Tecnologia e Ciências Sociais - DTCS do Campus III UNEB em Juazeiro - Bahia no período de setembro a dezembro de 2015. Foram cultivadas um total de 139 mudas do maxixe Liso Calcutá e 19 mudas do maxixe Crioulo, no espaçamento de 3,0×1,0m e irrigadas por gravidade. O cultivo adotado nesta área foi o convencional. O acompanhamento da floração mostrou que a variedade Crioula foi mais precoce que a Liso Calcutá, porém a segunda apesar de apresentar menor relação frutos/planta, registrou um maior volume (peso) de produção, sendo assim a mais indicada para produção em larga escala.
\end{abstract}

Palavras-chave: Cucumis anguria; Biologia Floral; Floração.

\section{FLOWERING AND FLORAL BIOLOGY OF GHERKIN}

Abstract: The gherkin production is almost totally subspontaneous, with low yield and fruit quality. Studies showed that the gherkin production depends on the cross pollination carried out mainly through the accomplishment of this process when visiting as flowers. Little is known about the floral biology of gherkin. In this way, the objective of this work was to record the flowering period, the sexual relation between floral types and aspects of floral biology such as viability and pollen germination, stigma receptivity, nectar volume and pollen grains quantity per anther. The experiment was conducted in an experimental area in the Department of Technology and Social Sciences DTCS, Campus III - UNEB in Juazeiro-Bahia from September to December, 2015. A total of 139 plants gherkin Liso Calcutá and 19 gherkin Crioulo, in spacing of 3,0 $\times 1,0 \mathrm{~m}$ and irrigated by furrow. The cultivation adopted in this area was the conventional one. The flowering monitoring showed that the Crioulo variety was earlier than Liso Calcutá, but the second one, despite having a lower 
fruits/plant ratio, registered a larger production volume (weight), thus being the best indicated for large scale production.

Keywords: Cucumis anguria; Floral Biology; Flowering.

\section{INTRODUÇÃO}

O maxixe (Cucumis anguria L.) é uma olerícola pertencente à família das cucurbitáceas, também conhecido como "pepino do oeste indiano" ou "pepino indiano", pertencente ao mesmo gênero do melão (Cucumis melo L.) (KIRKBRIDE, 1993; ROBINSON e DECKER-WALTERS, 1997). O maxixe é uma cultura de origem africana, introduzida no Brasil a cerca de 300 anos em decorrência do tráfico de escravos. O maxixeiro pode ser encontrado nas regiões tropicais e subtropicais do planeta, estendendo sua ocorrência à África Tropical, no Norte e Nordeste do Brasil, Caribe e Estados Unidos (MADEIRA et al., 2008; MANGAN et al., 2008).

A planta é monoica, anual, com caule rasteiro, ramificado, anguloso e áspero, de hábitos de crescimento indeterminado e prostrado (STASI e HIRUMA-LIMA, 2002). As flores são de sexos separados e dispostas em inflorescências racemosas reduzidas: as masculinas, em número de três a dez por inflorescência; a inflorescência feminina contém uma única flor (KIRKBRIDE, 1993). As flores femininas apresentam ovário ínfero, com inúmeros nectários. As flores masculinas são fasciculadas, com pedicelo curto e filiforme; cálices campanulados, hirsutos e com 5-7 mm de comprimento; corola de $1 \mathrm{~cm}$ de comprimento; estames com filetes glabros, com 1-2 mm de comprimento e conectivo apendiculado (CORRÊA, 1974). Os frutos apresentam grande variabilidade quanto ao formato, presença e ausência de espículos e sabor amargo (LOWER e EDWARD, 1986; MELO e TRANI, 1998). Outra característica é a presença de considerável adaptabilidade a condições adversas, como rusticidade e reduzida necessidade hídrica (FILGUEIRA, 2003).

Na região Nordeste do Brasil, a produção do maxixeiro é quase que exclusivamente de forma subespontânea nascendo em áreas cultivadas com outras espécies, como o feijão e o milho, de forma que não são realizadas práticas culturais específicas, resultando em baixo rendimento e qualidade de frutos (OLIVEIRA et al., 2014). Por ser uma planta muito resistente durante o seu desenvolvimento não se utiliza defensivos agrícolas, sendo assim considerada uma hortaliça naturalmente orgânica (DUARTE et al., 2015a). É considerada uma hortaliça subutilizada pelo sistema de produção, portanto, não havendo muitas informações quanto a sua produção (SILVA et al., 2008). Atualmente novos mercados estão se abrindo para o maxixe, como por exemplo, na forma de conserva (NASCIMENTO et al., 2011).

A colheita inicia-se de 50 - 70 dias após a semeadura, prolongando-se por um período de três meses ou mais (MODOLO, 2003). O ponto de colheita depende da forma de utilização do maxixe. No consumo in natura, na forma de salada, ou em conserva, como picles, os frutos devem ser colhidos antes que se complete a formação da semente (MODOLO, 2003). 
O consumo de maxixe, na média nacional, ainda é muito baixo, com aquisição per capita em torno de $0,067 \mathrm{~kg} \mathrm{ano}^{-1}$, sendo os maiores índices de aquisição também nas regiões Norte e Nordeste, com 0,172 e 0,130 kg ano-1 (IBGE, 2012). Seus frutos podem ser processados na forma de conservas, apresentando boa aceitação pelos consumidores, maior vida de prateleira, elevado rendimento e baixo custo de produção, tornando-o produto comercializável durante todo o ano e com preço acessível (NASCIMENTO et al., 2011).

As cucurbitáceas são um grupo de plantas muito estudadas quanto à polinização, que em sua maioria, dependem de agentes polinizadores (SERRA e CAMPOS, 2010). Apesar de raros, um estudo no estado do Maranhão comprovou que com a restrição das visitas de insetos polinizadores às flores do maxixeiro não foi registrada a formação de frutos, mostrando assim a necessidade dos agentes polinizadores. Neste mesmo trabalho, foram registradas três espécies de abelhas, Trigona cfr. guianae, Apis mellifera e Augochlora sp., sendo a primeira espécie a mais frequente (SOUZA et al., 2013). Entretanto, outro estudo realizado em Juazeiro-BA, registrou a $A$. mellifera como a mais frequente no cultivo e a considerou como polinizadora efetiva do maxixeiro (SILVA, 2015).

Fica evidenciado que a produção de maxixe depende da polinização cruzada realizada principalmente por abelhas. As abelhas atuam ativamente na coleta de néctar e pólen das flores, pois, alimentam-se quase que exclusivamente destes recursos e precisam visitar um grande número de flores para satisfazerem suas necessidades individuais, das crias e da colônia, garantindo durante esse processo, a transferência de material genético de uma planta para outra (CORBET et al., 1991; LIMA et al., 2012).

Desta forma, o objetivo desse trabalho foi registrar os aspectos da floração como, período, relação sexual entre os tipos florais e dados da biologia floral como a viabilidade e germinação polínica, receptividade do estigma, volume de néctar e a quantidade de grãos de pólen por antera.

\section{MATERIAL E MÉTODOS}

O experimento foi conduzido no Departamento de Tecnologia e Ciências Sociais - DTCS do Campus III - UNEB em Juazeiro-Bahia (09²5'43.6”S, 40³2'14”W, 384m) no período de setembro a dezembro de 2015. O clima da região segundo a classificação de Köppen é BSwh' quente seco, semiárido com precipitação pluviométrica média anual de $542 \mathrm{~mm}$, com as chuvas concentradas no período de novembro a abril (EMBRAPA, 2015).

Foram utilizadas sementes da variedade comercial Liso Calcutá e Crioula. Sendo que a variedade crioula foi doada por produtores do município de Euclides da Cunha-BA. As mudas foram preparadas em bandejas de polipropileno com 200 células preenchidas com substrato comercial Plantmax ${ }^{\circledR}$ e transplantadas quando apresentaram a segunda folha verdadeira. $O$ solo foi preparado com aração e gradagem. Foram cultivadas um total de 139 mudas do maxixe Liso Calcutá e 19 mudas do maxixe Crioulo, no espaçamento de 3,0×1,0m e irrigadas por gravidade. $O$ cultivo adotado nesta área foi o convencional. 
No início da floração, foram selecionadas aleatoriamente 20 plantas da cultivar Liso Calcutá e 12 do Crioulo, marcadas com fitas coloridas e acompanhadas durante todo o período de floração, sendo contados o número de flores por tipo floral duas vezes por semana.

Para a determinação do volume do néctar, foram ensacadas em pré-antese 5 flores masculinas e 3 femininas aleatoriamente por horário de avaliação das duas variedades em estudo. No dia seguinte foram coletadas nos horários de 09, 13 e 17 horas, totalizando 15 flores masculinas e 9 flores femininas. Como o volume de néctar era muito pequeno optou-se por usar a técnica do ponto descrita por Kearns e Inouye (1993). Para esta técnica utilizou-se papel de filtro com as seguintes especificações: velocidade de filtração rápida, grau quantitativo 30 e porosidade $7,5 \mu \mathrm{m}$.

$\mathrm{Na}$ determinação do percentual de viabilidade polínica, as flores masculinas foram ensacadas em pré-antese, e nos intervalos de 7, 9, 11, 13 e 15 horas, foram coletadas quinze flores masculinas, três em cada horário e levadas ao laboratório para avaliação, que consistiu na maceração das anteras em lâmina com posterior adição de Carmim acético a 2\%; em seguida procedia-se a contagem de 300 grãos, sendo os mesmos classificados em viáveis, quando corados, e inviáveis, quando não corados. Foram mensurados o tamanho dos grãos, utilizando ocular micrométrica, sendo avaliados 40 grãos viáveis e inviáveis, por variedade. Foi testada também a receptividade do estigma em três flores femininas por horário, nos intervalos de 9, 13 e 17 horas, com a aplicação de gotas de peróxido de hidrogênio $\left(\mathrm{H}_{2} \mathrm{O}_{2}\right)$ a 10 vol sobre a superfície estigmática, demonstrando-se receptivo quando havia formação de bolhas (ZEISLER, 1938).

Para a avaliação da germinação dos grãos de pólen in vitro, foi testado o meio de cultura proposto por BrewBaker e Kwack (1963) sendo que, um continha 10\% de sacarose (Meio 1) e outro $5 \%$ de sacarose (Meio 2). Os elementos componentes dos meios foram dissolvidos em água destilada e aquecidos em forno microondas até a dissolução completa dos componentes (VEIGA et al., 2012). Os meios foram distribuídos em cinco lâminas duplamente escavadas, utilizadas para visualização em microscópio óptico, sendo cada côncavo da superfície da lâmina equivalente a uma repetição. Foram ensacadas 12 flores masculinas de cada variedade em pré-antese. No dia seguinte foram coletadas e levadas para o laboratório sendo retirada suas anteras, e os grãos de pólen extraídos em água saturada com sacarose para evitar que os mesmos estourassem. Após verter o meio nas lâminas, os grãos de pólen foram distribuídos. Decorridas duas horas foi realizada a contagem dos grãos de pólen germinados, sob microscópio óptico com objetiva de 40x, considerando-se germinados aqueles que apresentavam o comprimento do tubo polínico igual ou superior ao diâmetro do próprio grão de pólen (FRAZON e RASEIRA, 2006), e o resultado foi expresso em porcentagem.

Para estimar a quantidade de pólen por flor, foram escolhidas aleatoriamente três flores masculinas em pré-antese de cada variedade, levadas ao laboratório e com o auxílio do estereomicroscópio, estiletes e pinças, foi separada uma antera de cada flor, sendo estas posteriormente colocadas em lâmina de vidro, maceradas em solução de água com açúcar, para 
evitar que ocorresse a lise dos grãos e sob microscópio óptico com objetiva de 40x, foram contados os grãos. O número obtido foi multiplicado por três, para obtenção do número total de grãos de pólen por flor.

Foram colhidos cinco frutos de cada planta utilizada para o acompanhamento floral, para a realização da avaliação pós-colheita em laboratório, sendo avaliado as seguintes características: massa, comprimento do fruto, diâmetro do fruto, espessura da casca, espessura da polpa, o número de sementes, produção de frutos por planta e produtividade por hectare.

Os dados obtidos foram submetidos à análise de variância e os tratamentos comparados pelo teste de Tukey a 5\% de probabilidade, utilizando o programa STATISTICA 8.0.

\section{RESULTADOS E DISCUSSÃO}

A antese floral ocorreu por volta de $5 \mathrm{~h}: 00 \mathrm{~min}-6 \mathrm{~h}: 00 \mathrm{~min}$, como observado também por Kiill et al. (2014) no meloeiro, e a senescência ocorreu em média por volta de 17h:00min-18h:00min. Na cultivar Liso Calcutá, a emissão de flores registrada inicialmente foi de masculinas, permanecendo o seu número mais elevado que as flores femininas em todo o período de floração estudado (Figura 1). Esta característica também foi registrada em plantas de melancieira (Citrullus lanatus) e meloeiro (Cucumis melo) em Juazeiro-BA, o que parece ser um padrão característico em cucurbitáceas (SIQUEIRA et al., 2011; DUARTE et al., 2015b). O maior número de flores masculinas em relação à feminina garante um maior fluxo de pólen no cultivo, garantindo assim a polinização, desde que haja o agente polinizador.

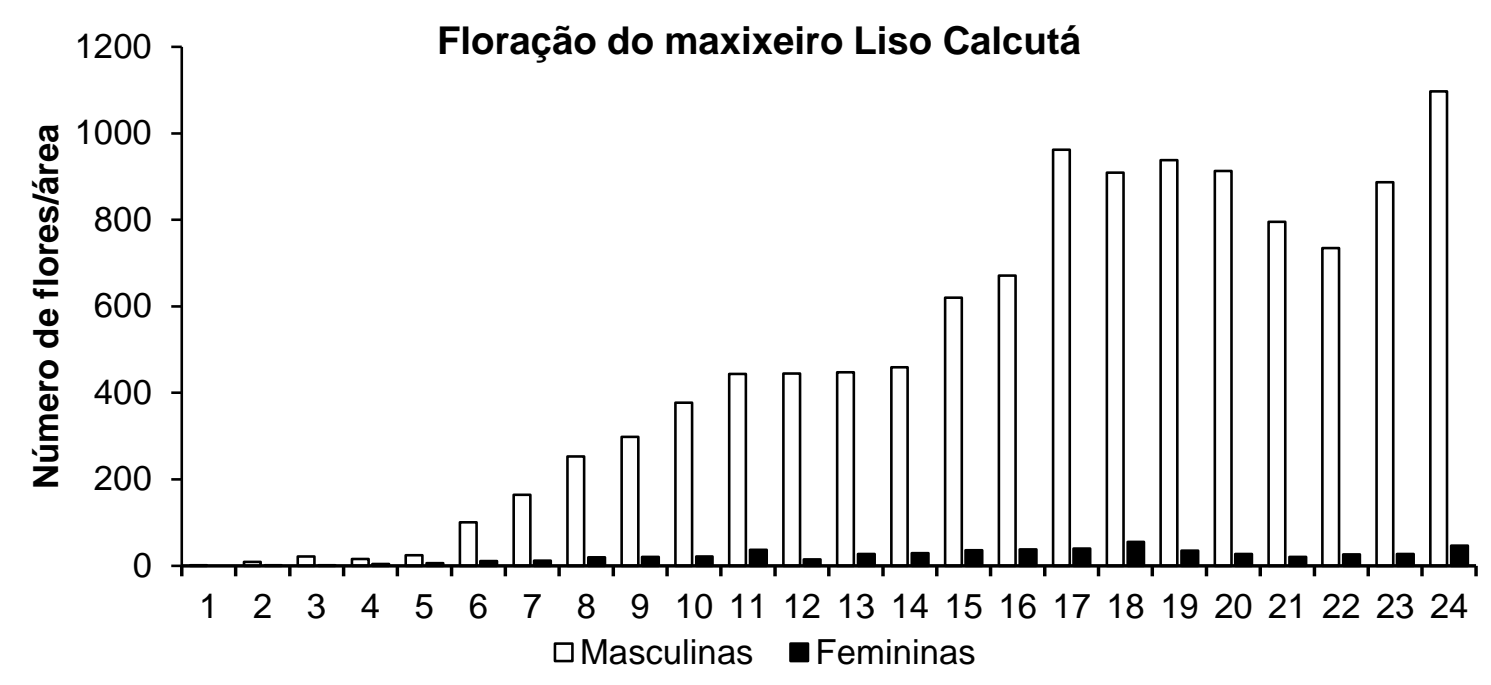

Figura 1. Período de floração da cultivar Liso Calcutá, em área experimental da Universidade do Estado da Bahia - UNEB, campus III, Juazeiro-BA, 2015.

O maior pico de flores masculinas foi registrado na contagem 24 (12 $2^{\text {a }}$ semana após o transplantio), e de flores femininas na contagem 18 (9a semana após o transplantio). É importante 
ressaltar que o maior número de flores masculinas, além de servir como atrativo inicial para as abelhas polinizadoras, por ofertar pólen e néctar, são importantes na determinação do fluxo de pólen na população (DUARTE et al., 2015b), como já discutido anteriormente.

Diferentemente da cultivar Liso Calcutá, o acesso Crioulo inicialmente emitiu flores femininas, comportamento não observado em outras cucurbitáceas por Siqueira et al. (2011) e por Duarte et al. (2015b), em plantas de meloeiro e melancieira, respectivamente. O maior número de flores masculinas registradas foi na contagem 15 ( $8^{\text {a }}$ semana após o transplantio), e de flores femininas foi na contagem 8 (4aㅗ semana após o transplantio), diferente do Liso Calcutá (Figura 2).

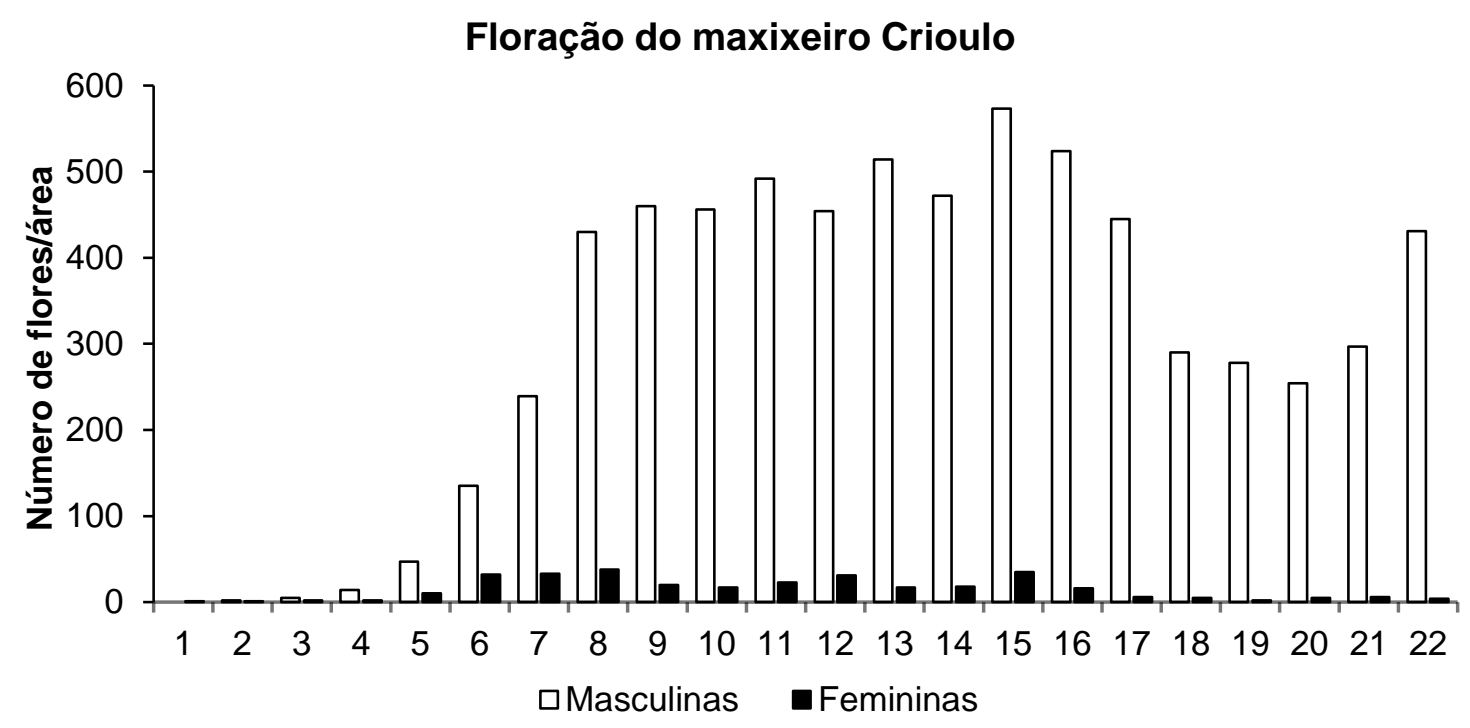

Figura 2. Período de floração do acesso Crioulo, em área experimental da Universidade do Estado da Bahia - UNEB, campus III, Juazeiro-BA, 2015.

A razão sexual obtida durante o experimento na cultivar Liso Calcutá foi 1:20,76, ou seja, uma flor feminina para 20,76 flores masculinas; e para o acesso Crioulo foi 1:21,02. Esta relação superior de flores masculinas em relação às femininas ou hermafroditas é comum em cucurbitáceas (SIQUEIRA et al., 2011).

A presença de flores femininas e masculinas solitárias mostra a necessidade da transferência dos grãos de pólen por vetores bióticos, especialmente por abelhas melíferas (ARAÚJO et al., 2014). A atratividade de uma florada pode ser influenciada por características endógenas à planta como, por exemplo, a quantidade de néctar e pólen acessíveis às abelhas e a concentração de flores na planta (RAMALHO et al., 1985; RAMALHO et al., 2007).

Quanto ao néctar, quando comparado por horário, as flores masculinas do maxixeiro Liso Calcutá produzem maior volume em relação ao Crioulo, apresentando diferença estatística no período de 13:00h, sendo que, a partir deste horário houve uma maior produção de néctar. Isso pode ser devido à menor disponibilidade de pólen necessitando, desta forma, de maior volume de néctar para atrair os visitantes florais (Tabela 1). 
Tabela 1. Volume médio de néctar em $\mu \mathrm{L}$ nas flores masculinas das variedades Liso Calcutá e Crioulo durante o dia, em Juazeiro-BA, 2015.

\begin{tabular}{lccc}
\hline \multirow{2}{*}{ Variedades } & \multicolumn{3}{c}{ Horário de avaliação } \\
\cline { 2 - 4 } & $09: 00 \mathrm{~h}$ & $13: 00 \mathrm{~h}$ & $17: 00 \mathrm{~h}$ \\
\hline Liso Calcutá & $0,246 \pm 0,058 \mathrm{a}$ & $0,352 \pm 0,057 \mathrm{a}$ & $0,515 \pm 0,080 \mathrm{a}$ \\
Crioulo & $0,229 \pm 0,091 \mathrm{a}$ & $0,221 \pm 0,073 \mathrm{~b}$ & $0,459 \pm 0,100 \mathrm{a}$ \\
\hline
\end{tabular}

As médias na mesma coluna, seguidas pela mesma letra, não diferem estatisticamente entre si pelo Teste de Tukey ao nível de $5 \%$ de probabilidade.

As flores femininas do maxixeiro Liso Calcutá e Crioulo, têm o mesmo comportamento das masculinas, apresentando maior volume de néctar no horário de $17 \mathrm{~h}$. Porém, para o maxixeiro Crioulo o menos volume de néctar foi registrado no horário das $13 \mathrm{~h}$ (Tabela 2).

Tabela 2. Volume médio de néctar em $\mu \mathrm{L}$ nas flores femininas das variedades Liso Calcutá e Crioulo durante o dia, em Juazeiro-BA, 2015.

\begin{tabular}{lccc}
\hline \multirow{2}{*}{ Variedades } & \multicolumn{3}{c}{ Horário de avaliação } \\
\cline { 2 - 4 } & $09: 00 \mathrm{~h}$ & $13: 00 \mathrm{~h}$ & $17: 00 \mathrm{~h}$ \\
\hline Liso Calcutá & $0,583 \pm 0,194 \mathrm{a}$ & $0,888 \pm 0,434 \mathrm{a}$ & $1,183 \pm 0,445 \mathrm{a}$ \\
Crioulo & $0,678 \pm 0,333 \mathrm{a}$ & $0,305 \pm 0,026 \mathrm{a}$ & $1,390 \pm 0,723 \mathrm{a}$
\end{tabular}

As médias na mesma coluna, seguidas pela mesma letra, não diferem estatisticamente entre si pelo Teste de Tukey ao nível de $5 \%$ de probabilidade.

Quanto aos tipos florais da cultivar Liso Calcutá, as flores femininas ofertaram mais néctar em todos os horários avaliados quando comparadas com as masculinas. Sendo um mecanismo conhecido das cucurbitáceas que produzem mais néctar nas flores femininas para aumentar a atração dos agentes polinizadores, elevando, desta forma, a possibilidade de reprodução (Tabela 3). As flores femininas das plantas monoicas produzem mais néctar do que as masculinas, o que poderia também ser uma estratégia para atrair os polinizadores (ASHWORTH et al., 2002).

Tabela 3. Volume médio de néctar em $\mu \mathrm{L}$ nos tipos florais da Variedade Liso Calcutá durante o dia, em Juazeiro-BA, 2015.

\begin{tabular}{lccc}
\hline \multirow{2}{*}{ Flor } & \multicolumn{3}{c}{ Horário de avaliação } \\
\cline { 2 - 4 } & $09: 00 \mathrm{~h}$ & $13: 00 \mathrm{~h}$ & $17: 00 \mathrm{~h}$ \\
\hline Masculina & $0,246 \pm 0,058 \mathrm{~b}$ & $0,352 \pm 0,057 \mathrm{~b}$ & $0,515 \pm 0,080 \mathrm{~b}$ \\
Feminina & $0,583 \pm 0,194 \mathrm{a}$ & $0,888 \pm 0,434 \mathrm{a}$ & $1,183 \pm 0,445 \mathrm{a}$
\end{tabular}

As médias na mesma coluna, seguidas pela mesma letra, não diferem estatisticamente entre si pelo Teste de Tukey ao nível de $5 \%$ de probabilidade.

Para a variedade Crioula, a flor feminina apresentou maior volume de néctar no horário da manhã e fim da tarde em relação às flores masculinas, porém, no horário de $13 \mathrm{~h}$ não apresentou diferença significativa (Tabela 4). 
Tabela 4. Volume médio de néctar em $\mu \mathrm{L}$ nos tipos florais da Variedade Crioula durante o dia, em Juazeiro-BA, 2015.

\begin{tabular}{lccc}
\hline \multirow{2}{*}{ Flor } & \multicolumn{3}{c}{ Horário de avaliação } \\
\cline { 2 - 4 } & $09: 00 \mathrm{~h}$ & $13: 00 \mathrm{~h}$ & $17: 00 \mathrm{~h}$ \\
\hline Masculina & $0,229 \pm 0,091 \mathrm{~b}$ & $0,221 \pm 0,073 \mathrm{a}$ & $0,459 \pm 0,100 \mathrm{~b}$ \\
Feminina & $0,678 \pm 0,333 \mathrm{a}$ & $0,305 \pm 0,026 \mathrm{a}$ & $1,390 \pm 0,723 \mathrm{a}$ \\
\hline
\end{tabular}

As médias na mesma coluna, seguidas pela mesma letra, não diferem estatisticamente entre si pelo Teste de Tukey ao nível de $5 \%$ de probabilidade.

O número médio de grãos de pólen por antera para o maxixeiro Liso foi de 1.843,66 £67,67, tendo em média 5.530,98 grãos por flor, e para o maxixeiro Crioulo por antera foi 2.099,33 $\pm 78,62$, e em média 6.297,99 grãos por flor, apresentando diferença significativa (Tabela 5).

Tabela 5. Número de grãos de pólen por antera e por flor masculina nas variedades Liso Calcutá e Crioula, em Juazeiro-BA, 2015.

\begin{tabular}{lcc}
\hline Variedade & № por antera & № por flor \\
\hline Liso Calcutá & $1.843,66 \pm 67,67 \mathrm{~b}$ & $5.530,98$ \\
Crioula & $2.099,33 \pm 78,62 \mathrm{a}$ & $6.297,99$ \\
Média Geral & 1971,50 & -
\end{tabular}

As médias na mesma coluna, seguidas pela mesma letra, não diferem estatisticamente entre si pelo Teste de Tukey ao nível de $5 \%$ de probabilidade.

Os grãos de pólen estavam disponíveis nas anteras durante todo o dia, apresentando viabilidade polínica média de $94,1 \%$ para o maxixe Liso e $95,8 \%$ para o maxixe Crioulo. A quantidade de grãos viáveis excedeu de forma bastante expressiva a de inviáveis, o que favorece a fecundação e, consequentemente, favorecerá o desenvolvimento de frutos (ARAÚJO et al., 2011). Simultaneamente, o estigma foi receptivo em todos os horários avaliados. Esses dados são cruciais, pois o sucesso do pegamento dos frutos depende da relação entre o pólen e o estigma, que por sua vez pode ser influenciada pela viabilidade dos grãos, a receptividade do estigma e as alterações genéticas entre as partes (BUENO e CAVALCANTE, 2001).

Avaliando o percentual de germinação in vitro do pólen, observou-se que o Meio 1 contendo $10 \%$ de sacarose não houve nenhum grão germinado. Ao contrário, o Meio 2 contendo $5 \%$ de sacarose houve germinação, com percentual médio de 6,36 e 13,57\%, para o maxixeiro Liso Calcutá e Crioulo, respectivamente. Muitos fatores podem interferir na germinação dos grãos de pólen in vitro, entre eles destacam-se: o genótipo da planta, o momento da coleta, as condições de armazenagem, a composição do meio de cultura e a temperatura no momento da germinação (SEZERINO e ORTH, 2015).

Não foi encontrada diferença estatística entre os tamanhos dos grãos de pólen viáveis na vista equatorial e polar, diferente dos grãos de pólen inviáveis, os quais apresentaram diferença estatística, sendo que a variedade Crioula apresentou maior tamanho em relação à variedade Liso 
Calcutá. Observou-se também que os grãos de pólen inviáveis são menores que os viáveis (Tabela $6)$.

Tabela 6. Tamanho médio em $\mu \mathrm{m}$ dos grãos de pólen viáveis e inviáveis na Vista Polar (VP) e Equatorial (VE) das variedades Liso Calcutá e Crioula, em Juazeiro-BA, 2015.

\begin{tabular}{lcccc}
\hline \multirow{2}{*}{ Variedades } & \multicolumn{2}{c}{ Viáveis } & \multicolumn{2}{c}{ Inviáveis } \\
\cline { 2 - 5 } & V.P. & V. E. & V. & V. E. \\
\hline Liso Calcutá & $48,83 \pm 2,59$ a & $50,44 \pm 2,88$ a & $37,38 \pm 3,78 \mathrm{~b}$ & $40,21 \pm 4,67 \mathrm{~b}$ \\
Crioulo & $49,73 \pm 2,42 \mathrm{a}$ & $51,29 \pm 2,39 \mathrm{a}$ & $41,09 \pm 4,27 \mathrm{a}$ & $45,09 \pm 5,79 \mathrm{a}$ \\
Média Geral & 49,28 & 50,86 & 39,23 & 42,65
\end{tabular}

As médias na mesma coluna, seguidas pela mesma letra, não diferem estatisticamente entre si pelo Teste de Tukey ao nível de $5 \%$ de probabilidade.

De acordo com a análise pós-colheita dos frutos, foram encontradas diferenças significativas para todas as características avaliadas (Tabela 7). A cultivar Liso Calcutá apresentou as melhores características quando comparada com o acesso Crioulo, demonstrando dessa forma uma superioridade da cultivar Liso Calcutá (DUARTE et al., 2015a).

Tabela 7. Análise pós-colheita dos frutos de maxixeiro Liso Calcutá e Crioulo, em Juazeiro-BA, 2015.

\begin{tabular}{lcccccc}
\hline Variedade & Massa $(\mathrm{g})$ & $\begin{array}{c}\text { Comprimento } \\
\text { do fruto }(\mathrm{mm})\end{array}$ & $\begin{array}{c}\text { Diâmetro } \\
\text { do fruto } \\
(\mathrm{mm})\end{array}$ & $\begin{array}{c}\text { Espessura } \\
\text { da casca } \\
(\mathrm{mm})\end{array}$ & $\begin{array}{c}\text { Espessura } \\
\text { da polpa } \\
(\mathrm{mm})\end{array}$ & $\begin{array}{c}\text { Número } \\
\text { de }\end{array}$ \\
\hline $\begin{array}{l}\text { Liso } \\
\text { Calcutá }\end{array}$ & $32,73 \mathrm{a}$ & $52,65 \mathrm{a}$ & $35,02 \mathrm{a}$ & $1,52 \mathrm{a}$ & $31,42 \mathrm{a}$ & $144,68 \mathrm{~b}$ \\
Crioulo & $19,60 \mathrm{~b}$ & $44,59 \mathrm{~b}$ & $27,75 \mathrm{~b}$ & $1,15 \mathrm{~b}$ & $25,25 \mathrm{~b}$ & $201,28 \mathrm{a}$ \\
\hline
\end{tabular}

As médias na mesma coluna, seguidas pela mesma letra, não diferem estatisticamente entre si pelo Teste de Tukey ao nível de $5 \%$ de probabilidade.

O maxixe comum apresenta massa média variando de 14,57 a 45,70 g dependendo da cultivar, da época de plantio e da região produtora (PIMENTEL, 1985; RESENDE, 1998). Duarte et al. (2015a) registrou em seu experimento para o maxixe Crioulo e Liso Calcutá média de peso/fruto de 19,71 e 43,46 g, respectivamente, concordando com os resultados encontrados neste experimento (Tabela 7). Resultados semelhantes foram encontrados por Medeiros (2009), cultivando Maxixe do Norte, com massa média de 15,81 a 22,66 g; e por Oliveira et al. (2010) com a cultivar Nordestino, estudando diferentes espaçamentos, sendo que no espaçamento $3 \times 1 \mathrm{~m}$ encontrou massa média de $38 \mathrm{~g}$.

O maxixe Liso tem maior peso, diâmetro, comprimento do fruto, maior espessura da polpa e menos sementes, portanto, sendo a cultivar mais indicada para a comercialização por possuir melhores características para consumo. A produção média foi de 18,77 frutos/planta para o 
maxixeiro Liso Calcutá, e 23,58 frutos/planta para o maxixeiro Crioulo, determina neste experimento uma produtividade de $31.283,33$ frutos/ha (1,02 t/ha) e 39.300 frutos/ha $(0,77$ t/ha), respectivamente.

\section{CONCLUSÃO}

A floração da variedade Crioula foi mais precoce que a do Liso Calcutá, porém a segunda apesar de apresentar menor relação frutos/planta em relação a Crioula, apresentou maior volume de produção (peso), sendo assim, a mais indicada para produção em larga escala.

\section{REFERÊNCIAS}

ARAÚJO, D. C. S.; GAMA, D. R. S.; SILVA, N. C.; COELHO, M. S.; SIQUEIRA, K. M. M. Viabilidade polínica de botões em pré-antese dos tipos florais do melão amarelo (Cucumis melo L. CUCURBITACEAE). In: 62 Congresso Nacional de Botânica, 2011, Fortaleza, Ceará. Botânica e Desenvolvimento Sustentável. Fortaleza: Editora da Universidade Estadual do Ceará, 2011.

ARAÚJO, D. C. S.; SIQUEIRA, K. M. M.; DUARTE, P. M. D.; SILVA, N. C. Comportamento de forrageamento de Apis mellifera na melancieira (Citrullus lanatus) no município de Juazeiro, BA. Revista Verde de Agroecologia e Desenvolvimento Sustentável, 09(1), 59-67, 2014.

ASHWORTH, L.; GALETTO, L. Differential néctar production between male and female flowers in a wild cucurbit; Cucurbita maxima ssp. Andreana (Cucurbitaceae). Canadian Journal of Botany, 80, 1203-1208, 2002.

BREWBAKER, J. L.; KWACK, B. H. The essential role of calcium ion in pollen germination and pollen tube growth. American Journal of Botany, 50(9), 859-865, 1963.

BUENO, D. M.; CAVALCANTE, K. L. Estudo da viabilidade dos grãos de pólen de flores de melão (Cucumis melo L.). Fortaleza-CE. 2001.

CORBET, S. A.; WILLIAMS, I. H.; OSBORNE, J. L. Bees and pollination of crop and wild flowers in the European Community. Bee World, 72(2), 47-59, 1991.

CORRÊA, M. P. Dicionário das plantas úteis do Brasil e das exóticas cultivadas. Rio de Janeiro: IBDF/Ministério da Agricultura, v.1, 1689 p., 1974.

DUARTE, P. M.; SILVA, G. B. S.; SILVA, N. C.; CARNEIRO-NETO, T. F. S.; SIQUEIRA, K. M. M. Produção do maxixeiro (Cucumis anguria L.), Crioulo e a cultivar comercial Liso Calcutá. In: XI SEMBIO: Uma discussão acerca da diversidade nos biomas brasileiros. Paulo Afonso: ano 5, v.5, p. 30-33, 2015a.

DUARTE, P. M.; SIQUEIRA, K. M. M.; SILVA, N. C.; SILVA, G.B.S.; GOMES, I. L. S. Floração e morfologia floral de variedades de melancieira em Juazeiro-BA. Revista Verde de Agroecologia e Desenvolvimento Sustentável, 10(3), 72-76, 2015b.

EMBRAPA. Dados Meteorológicos, Estação Agrometeorológica de Mandacarú, Juazeiro-BA. Disponível em: www.cpatsa.embrapa.br. Acesso em: 04 jul. 2015.

FILGUEIRA, F. A. R. Novo manual de olericultura: agrotecnologia moderna na produção e comercialização de hortaliças. 2. ed. Viçosa: UFV, 2003. 358 p.

FRAZON, R. C.; RASEIRA, M. C. B. Germinação in vitro e armazenamento do pólen de Eugenia involucrata DC (Myrtaceae). Revista Brasileira de Fruticultura, 28(1), 18-20, 2006. 
IBGE - Instituto Brasileiro de Geografia e Estatística (2012) POF - Pesquisa de Orçamentos Familiares 2008 - 2009. Disponível em: http://www. ibge.gov.br. Acessado em: 05 jun. 2013.

KEARNS, C. A.; INOUYE, D. W. Tecniques for pollination biologists. Colorado: University Press of Colorado, 1993. 630 p.

KIILL, L. H. P.; SIQUEIRA, K. M. M.; COELHO, M.S.; SILVA, T. A.; GAMA, D. R. S.; ARAUJO, D. C. S.; PEREIRA NETO, J. Frequency and foraging behavior of Apis mellifera in two melon hybrids in Juazeiro, state of Bahia, Brazil. Anais da Academia Brasileira de Ciências, 86(4), 2049-2055, 2014.

KIRKBRIDE, Jr, J. H. Biosystematic monograph of the genus Cucumis (Cucurbitaceae). (Ed). Parkway Publishers, Boone, North Carolina, 1993.

LIMA, C. B. S.; RIBEIRO, M. F.; GAMA, F. C.; SILVA, S. R. Preferências de abelhas mandaçaia (Melipona mandacaia) na alimentação artificial. Magistra, 24, 228-233, 2012.

LOWER, R. L.; EDWARDS, M. D. Cucumber breeding. In: BASSETT, M.J. (Ed.) Breeding vegetable crops. Wesport: AVI, p. 173-207, 1986.

MADEIRA, N. R.; REIFSCHNEIDER, F. J. B.; GIORDANO, L. B. Contribuição portuguesa à produção e ao consumo de hortaliças no Brasil: uma revisão histórica. Horticultura Brasileira, Brasília, 26(4), 428-432, 2008.

MANGAN, F.; MENDONÇA, R.; MOREIRA, M.; NUNES, S.; FINGER, F.; BARROS, Z.; GALVÃO, H.; ALMEIDA, G.; SILVA, R.A.; ANDERSON, M. Production and marketing of vegetables for the ethnic markets in the United States. Horticultura Brasileira, 26(1), 6-14, 2008.

MEDEIROS, M. A. Maturação fisiológica em sementes de maxixe (Cucumis anguria L.). 2009. $37 \mathrm{f}$. Dissertação (Mestrado em Agronomia: Fitotecnia) - Universidade Federal Rural do Semiárido (UFERSA), Mossoró-RN, 2009.

MELO, A. M. T.; TRANI, P. S. Maxixe. In: FAHL, J.I.; CAMARGO, M.B.P.; et, al.; (Ed). Instruções agrícolas para as principais culturas econômicas. Campinas: Instituto Agronômico, 1998. 393 p. (IAC. Boletim Técnico, 200).

MODOLO, V. A.; COSTA, C. P.; Maxixe: uma hortaliça de tripla forma de consumo. Ed.19. Piracicaba. USP/ESALQ. 2003.

NASCIMENTO, A. M. C. B.; NUNES, R. G. F. L.; NUNES, L. A. P. L. Elaboração e avaliação química, biológica e sensorial de conserva de maxixe (Cucumis anguria L.). Revista Acta Tecnológica, 6(1), 123-136, 2011.

OLIVEIRA, A. P.; SILVA, J. A.; OLIVEIRA, A. N. P.; SILVA, D. F.; SANTOS, R. R.; SILVA, N. V. Produção do maxixeiro em função de espaçamentos entre fileiras e entre plantas. Horticultura Brasileira, 28(3), 344-347, 2010.

OLIVEIRA, F. A.; PINTO, K. S. O.; BEZERRA, M. S.; LIMA, L. A.; CAVANCANTE, A. L. G.; OLIVEIRA, M. K. T.; MEDEIROS, J. F. Tolerância do maxixeiro, cultivado em vasos, à salinidade da água de irrigação. Revista Ceres, 61(1), 147-154, 2014.

PIMENTEL, A. A. M. P. Oleiricultura no trópico úmido: hortaliças da Amazônia. São Paulo: Agronômica Ceres, 1985. 332 p.

RAMALHO, M.; IMPERATRIZ-FONSECA, V. L.; KLEINERT-GIOVANNINI, A. Exploitation of floral resources by Plebeia remota Holmberg (Apidae- Meliponinae). Apidologie, 16(3), 307-330, 1985. 
RAMALHO, M.; SILVA, M. D.; CARVALHO, A. L. Dinâmica de uso das fontes de pólen por Melipona scutellaris Latreile (Hymenoptera, Apidae): uma análise comparativa com Apis mellifera (Hymenoptera, Apidae) no domínio tropical atlântico. Neotropical Entomology, 36(1), 38-45, 2007.

RESENDE, G. M. Rendimento de cultivares de maxixe em função de épocas de cultivo. Horticultura Brasileira, 16(2), 167-171, 1998.

ROBINSON, R. W.; DECKER-WALTERS D. S. 1997. Cucurbits. New York: CAB International. 225 p.

SERRA, B. D. V.; CAMPOS, L. A. O. Polinização entomófila de abobrinha, Cucurbita moschata (Cucurbitaceae). Neotropical Entomology, 39(2), 153-159, 2010.

SEZERINO, A. A.; ORTH, A. I. Polinização da Pereira-Portuguesa em Bom Retiro-SC, Brasil. Revista Brasileira de Fruticultura, 37(4), 943-951, 2015.

SILVA, J. R.; TORRES, S. B.; MEDEIROS, M. A. A.; OLIVEIRA, I. R. S. Avaliação do potencial fisiológico de sementes de maxixe. Revista Caatinga, 21(4), 68-71, 2008.

SILVA, N. C. Biologia floral e polinização de Cucumis anguria L., em Juazeiro-BA. 2015. 42 f. Trabalho de Conclusão de Curso (Bacharelado em Engenharia Agronômica) - Universidade do Estado da Bahia, Bahia, 2015.

SIQUEIRA, K. M. M.; KIILL, L. H. P.; GAMA, D. R. S.; ARAÚJO, D. C. S.; COELHO, M. S. Comparação do padrão de floração e visitação do meloeiro do tipo amarelo em Juazeiro-BA. Revista Brasileira de Fruticultura, 473-478, 2011.

SOUZA, E. H. S.; SANTOS, R. N. V; SARAIVA, A. B; LEMOS, R. N. S. Polinizadores do maxixe em São Luiz - MA. In: Resumos do VIII Congresso Brasileiro de Agroecologia. Porto Alegre, 2013.

STASI, L. C. D.; HIRUMA-LIMA, C. A. Plantas Medicinais na Amazônia e na Mata Atlântica. 2.ed. São Paulo: Unesp. 2002. 604 p.

VEIGA, P. O. A.; VON-PINHO, R. G.; VON-PINHO, E. V. R.; VEIGA, A. D.; OLIVEIRA, K. C.; DINIZ, R. P. Meios de cultura para germinação de grãos de pólen de milho. Agrarian, 5(17), 206-211, 2012.

ZEISLER, M. Über die Abgrenzung der eigentlichen Narbenfläche mit Hilfe von Reaktionen. Beihefte zum Botanische Zentralblatt, Cassel, 58, 308-318,1938. 